\title{
Mathematical modeling by Monte Carlo method of defects in the structure of fibre composites using as a binder of polybutadiene oligomers
}

\author{
Oleg Figovsky ${ }^{1, a}$, Yury Potapov ${ }^{2}$, Dmitry Panfilov ${ }^{2, b}$, Sergey Kashtanov ${ }^{1}$, \\ Eugeny Yudin ${ }^{2}$ \\ ${ }^{1}$ International Nanotechnology Research Center "Polymate", Migdal Haemek, Israel \\ ${ }^{2}$ Voronezh State University of Architecture and Civil Engineering, \\ Voronezh, Russian Federation \\ ${ }^{a, b}$ E-mail address: figovsky@gmail.com ,panfilov_dv@vgasu.vrn.ru
}

\begin{abstract}
Production of materials with low content of structural defects. Application of Monte Carlo method to quantify fiber intersections in the rubcon structure with account of specified sizes of samples. The article presents quantity-content curves for a number of areas with the dimensions smaller than the diameter of the permissible inhomogeneity against fibreboard percentage. Analyzed quantitycontent curves for a number of areas with the dimensions smaller than the diameter of the permissible inhomogeneity against fibreboard percentage and proven influence of stress concentrators on material strength.
\end{abstract}

Keywords: Rubber concrete (rubcon); Dispersed reinforcement; Metal fibre

\section{INTRODUCTION}

Production of materials with low content of structure defects is one of the actual problems of the current material science. Generally, in process of production of new materials various defects are generated, such as micro and nanocracks, defects of crystal lattice package etc. Growth defects generated in the process of material production along with the defects generated in the course of material work may result in their degradation and reduction of lifetime.

Research in the field of fracture mechanics revealed that material defects may be generated in the process of their operation, and not at the phase of material production.

It is assumed that studies of fracture processes of brittle solids originated from the paper of Alan Griffiths "Fracture Phenomenon and Flow of Solids" published in 1921. In his paper Griffiths introduced a priori existence of micro cracks in material, thus explaining considerable reduction of theoretical strength of material. For the first time a model describing the fracture processes of brittle solids was developed. Based on this idea, a new section of deformable solid mechanics was developed - fracture mechanics. By means of elasticity theory apparatus, the key ratios were obtained, that up to now are actual and in demand. 
However, subsequent studies revealed that the processes going on at the micro level could not be described just on the basis of "macroscopic approach" methods.

Fundamental difference of microscopic method is that for crack initiation it is not absolutely necessary for the would-be crack nucleus to be present in a solid body. When considering the physical mechanisms of micro cracks initiation, two fundamental nucleation methods should be differentiated, depending on the "construction" material of the micro crack. A micro crack may originate from either diffusion of vacancies, or coalescence of dislocations.

The basic idea of this approach is that under the impact of external load additional, as related to equilibrium, vacancies appear in brittle bodies. Eventually, concentration of such vacancies increases, and when concentration of such vacancies exceeds equilibrium concentration in a solid body at the given temperature, they start coalescing with microvoid formation. According to this approach, microvoid is deemed initial component for subsequent growth of cracks.

Microvoid is generated and grows owing to diffusion of vacancies formed in brittle bodies under the load. The matter is that diffusion flow of vacancies toward void arises under the impact of non-equilibrium distribution of vacancies concentration caused by external mechanical load.

Given a crystal exposed to external mechanical impact, for example, to overall tension, extra defects will arise in the material. Redundant, as compared to equilibrium, concentration of vacancies may cause fluctuation nucleation of a microvoid. Following the nucleation, microvoids may transform into a crack, given the load exceeds the critical value. In this connection, it is vital to reveal the nature and stability criteria of nucleus form of a new phase, as in the process of growing the microvoid form may fluctuate, and its morphology may change. For example, a void with initial spherical shape may lose its stability while growing and may transform into ellipsoid etc.

\section{EXPERIMENT, RESULTS AND DISCUSSION}

Three kinds of fibers presented on Figure 1 were chosen for the experiment.

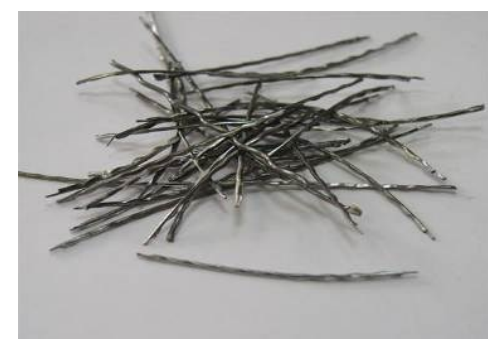

a

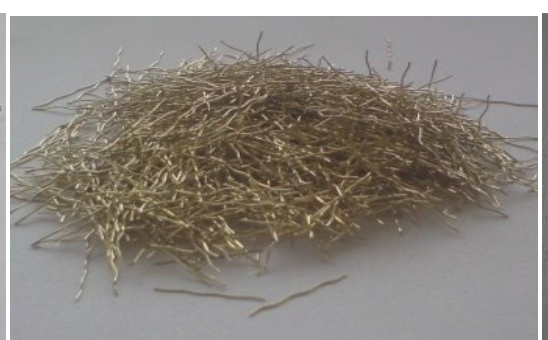

b

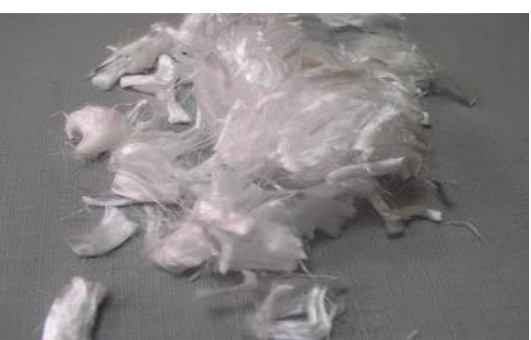

$\mathrm{c}$

Figure 1. Types of reinforcing fibres.

$a-$ steel chopped fibre $\mathrm{L}=40 \mathrm{~mm}, \mathrm{~d}=0.8 \mathrm{~mm}$;

$\mathrm{b}$ - steel brass plated fibre $\mathrm{L}=15 \mathrm{~mm}, \mathrm{~d}=0.3 \mathrm{~mm}$;

$\mathrm{c}$ - polypropylene fibre $\mathrm{L}=12 \mathrm{~mm}, \mathrm{~d}=12 \mu \mathrm{m}$.

For each kind of fibre, the quantity of fibres required for dispersed reinforcement of a standard sample with dimensions of $4 \times 4 \times 16 \mathrm{~cm}$ in volume fraction equal to $1,2,3$ and $4 \%$ was calculated. Due to the difference of the fibers in terms of size, mass and conventional 
diameter, with account of static distribution and permissible interval of $5 \%$, the values of fibre quantities presented in Table 1 were obtained.

Table 1. The values of fibre quantities.

\begin{tabular}{|c|c|c|c|c|}
\hline \multicolumn{2}{|c|}{} & \multicolumn{4}{|c|}{ Type of reinforcing fibre } \\
\cline { 2 - 5 } \multicolumn{2}{|c|}{} & $\begin{array}{c}\text { Steel chopped fibre } \\
\mathrm{L}=40 \mathrm{~mm}, \\
\mathrm{~d}=0.8 \mathrm{~mm}\end{array}$ & $\begin{array}{c}\text { Steel brass plated } \\
\text { fibre } \mathrm{L}=15 \mathrm{~mm}, \\
\mathrm{~d}=0.3 \mathrm{~mm}\end{array}$ & $\begin{array}{c}\text { Polypropylene fibre } \\
\mathrm{L}=12 \mathrm{~mm}, \\
\mathrm{~d}=12 \mu \mathrm{m}\end{array}$ \\
\hline \multirow{3}{*}{$\begin{array}{c}\text { Percentage } \\
\text { of fibre } \\
\text { content in a } \\
\text { sample }\end{array}$} & $1 \%$ & $124-130$ & $2450-2574$ & $1838800-1933000$ \\
\cline { 2 - 5 } & $2 \%$ & $248-260$ & $4900-5148$ & $3677600-3866000$ \\
\cline { 2 - 6 } & $4 \%$ & $374-390$ & $7350-7722$ & $5516400-5799000$ \\
\hline
\end{tabular}

Let us introduce regulation concerning necessary alternation with specific step of inhomogeneity and fibre centers of gravity by the shortest of distances possible between them, as the most probable crack propagation from one inhomogeneity to another should first of all progress in the direction corresponding to the minimal energy inputs required for material destruction. In general case, the fibre centers may be located by two structural schemes: in the centre of figure edges or on their peaks. Such arrangement of fibre centres in macroscopic cells are deemed the most optimal in terms of creating obstacles for crack development between inhomogeneity in rubcon.

As the fibre location in the material is chaotic, we may assume formation of areas where the distance between the fibre center of gravity is less than permissible inhomogeneity parameters.

Monte-Carlo method may be applied to determine quantitative characteristics of fibre intersection in the fibreboard structure with account of specified dimensions of the samples. The idea of this method consists in generation of multiple points with coordinates $(x, y, z)$, satisfying the following conditions:

- $\quad 0 \leq x \leq a$, where a - sample length, $\mathrm{m}$;

- $\quad 0 \leq y \leq b$, where $\mathrm{b}$ - sample breadth, $\mathrm{m}$;

- $\quad 0 \leq z \leq c$, where $\mathrm{c}-$ sample height, $\mathrm{m}$.

Geometric dimensions of the room are set in Cartesian rectangular coordinates XYZ so that the left lower angle coordinates are $(0,0,0)$ and the sample sides match the coordinates.

The value of permissible diameters of macroscopic inhomogeneity may be determined by the following formula: 


$$
d_{n}=\left(\frac{1.5 \cdot \mu_{n} \cdot d_{f}^{2} \cdot l_{f} \cdot n_{f c}}{\mu_{f}}\right)^{1 / 3}
$$

The results of permissible diameters of macroscopic inhomogeneity are presented in Table 2.

Table 2. The results of permissible diameters of macroscopic inhomogeneity.

\begin{tabular}{|c|c|c|c|c|c|c|c|}
\hline & & \multicolumn{6}{|c|}{ Type of reinforcing fibre } \\
\hline & & \multicolumn{2}{|c|}{$\begin{array}{l}\text { Steel chopped fibre } \\
\begin{array}{c}\mathrm{L}=40 \mathrm{~mm} \\
\mathrm{~d}=0.8 \mathrm{~mm}\end{array}\end{array}$} & \multicolumn{2}{|c|}{$\begin{array}{l}\text { Steel brass plated fibre } \\
\qquad \begin{array}{c}\mathrm{L}=15 \mathrm{~mm} \\
\mathrm{~d}=0.3 \mathrm{~mm}\end{array}\end{array}$} & \multicolumn{2}{|c|}{$\begin{array}{c}\text { Polypropylene fibre } \\
\mathrm{L}=12 \mathrm{~mm}, \\
\mathrm{~d}=12 \mu \mathrm{m}\end{array}$} \\
\hline \multicolumn{2}{|c|}{$\begin{array}{l}\text { Location of the } \\
\text { centre of gravity } \\
\text { of fibreboard }\end{array}$} & $\begin{array}{l}\text { On cell } \\
\text { peaks }\end{array}$ & $\begin{array}{l}\text { In the } \\
\text { center } \\
\text { of edges }\end{array}$ & $\begin{array}{l}\text { On cell } \\
\text { peaks }\end{array}$ & $\begin{array}{c}\text { In the cen- } \\
\text { ter } \\
\text { of edges }\end{array}$ & $\begin{array}{c}\text { On cell } \\
\text { peaks }\end{array}$ & $\begin{array}{l}\text { In the } \\
\text { center } \\
\text { of edges }\end{array}$ \\
\hline \multirow{4}{*}{$\begin{array}{l}\text { Percentage } \\
\text { of fibre } \\
\text { content in a } \\
\text { sample }\end{array}$} & $1 \%$ & 6,15 & 4,35 & 2,32 & 1,65 & 0,34 & 0,24 \\
\hline & $2 \%$ & 4,93 & 3,44 & 1,83 & 1,28 & 0,27 & 0,19 \\
\hline & $3 \%$ & 4,26 & 2,96 & 1,62 & 1,14 & 0,24 & 0,17 \\
\hline & $4 \%$ & 3,86 & 2,71 & 1,45 & 1,03 & 0,22 & 0,15 \\
\hline
\end{tabular}

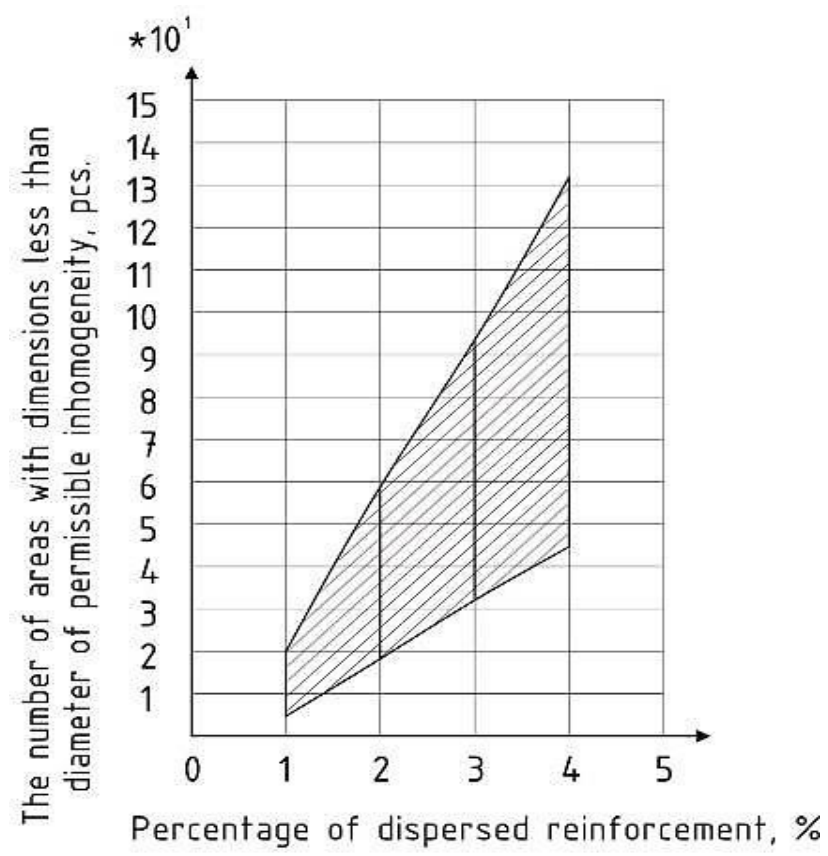

(a) 


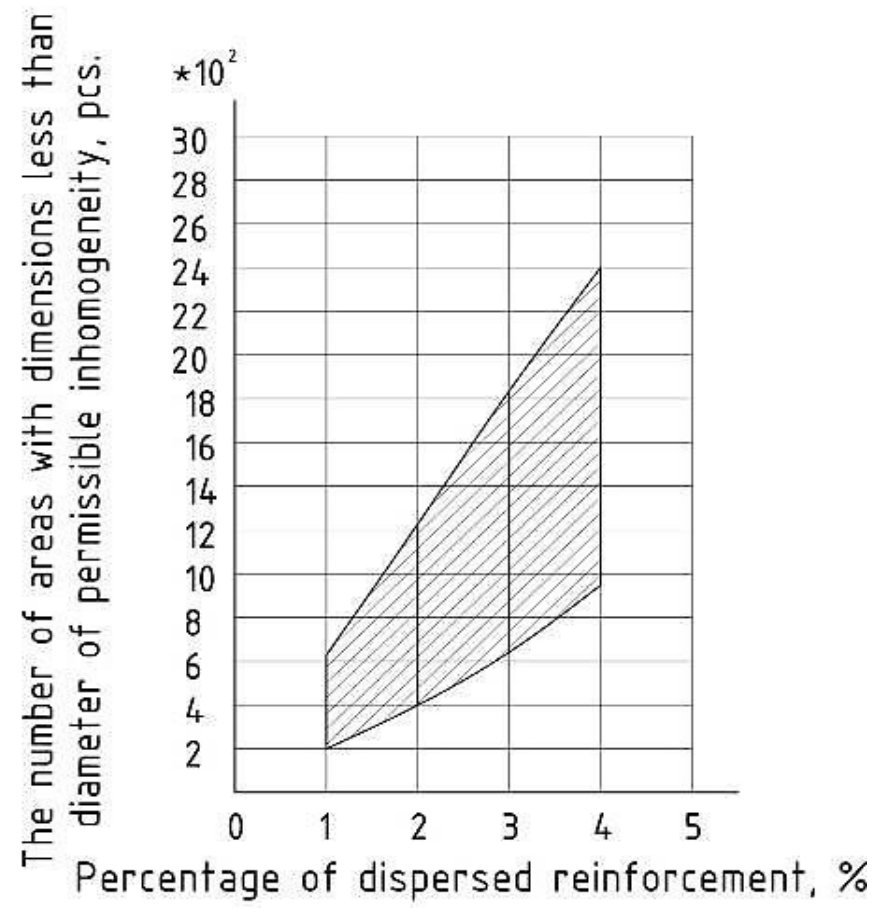

(b)

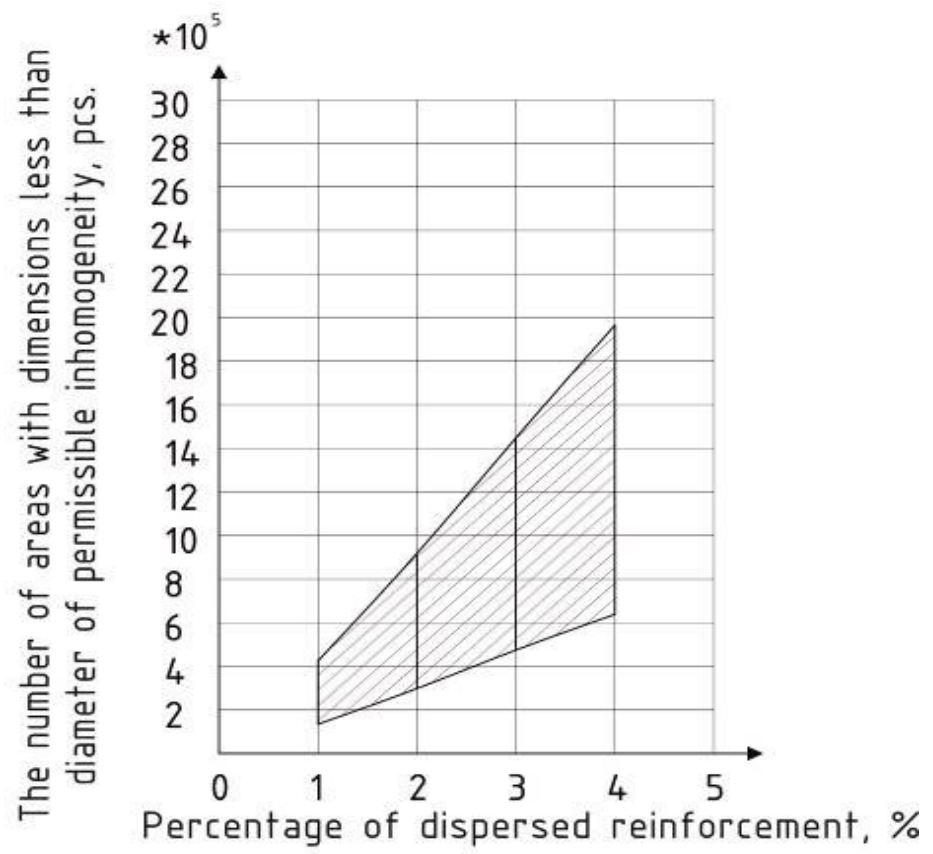

(c)

Figure 2. The number of areas with dimensions less than diameter of permissible inhomogeneity - fibreboard percentage curve.

a - steel chopped fibre $L=40 \mathrm{~mm}, d=0.8 \mathrm{~mm}$;

$\mathrm{b}$ - steel brass plated fibre $\mathrm{L}=15 \mathrm{~mm}, \mathrm{~d}=0.3 \mathrm{~mm}$;

c - polypropylene fibre $\mathrm{L}=12 \mathrm{~mm}, \mathrm{~d}=12 \mu \mathrm{m}$. 
The amount of intersected fibres in tested samples was calculated with stochastic model implemented in MatLab environment with application of Monte-Carlo method. The idea of this method consists in probabilistic scattering of the set amount of fibre within the sample volume.

Further, for each case the amount of fibres was selected at random to satisfy the data presented in Table 1, and the fibres were scattered within the volume limited to the specimen sizes. After that, the number of fibre intersections was calculated for the fibres with the distance between the centers of gravity being less than the prescribed threshold that is equal to the permissible inhomogeneity diameter - according to Table 2. The outputs of numerical experiments are presented on Figure 2.

The curve analysis revealed that with increase of fibreboard percentage in the material the number of "problem" areas increases where with by far greater probability material damage may originate. Correlating the obtained distributions with material strength presented on Figure 3, we can make a conclusion about the impact of stress concentrators in such areas on material strength in general.

$\sigma, \mathrm{MPa}$

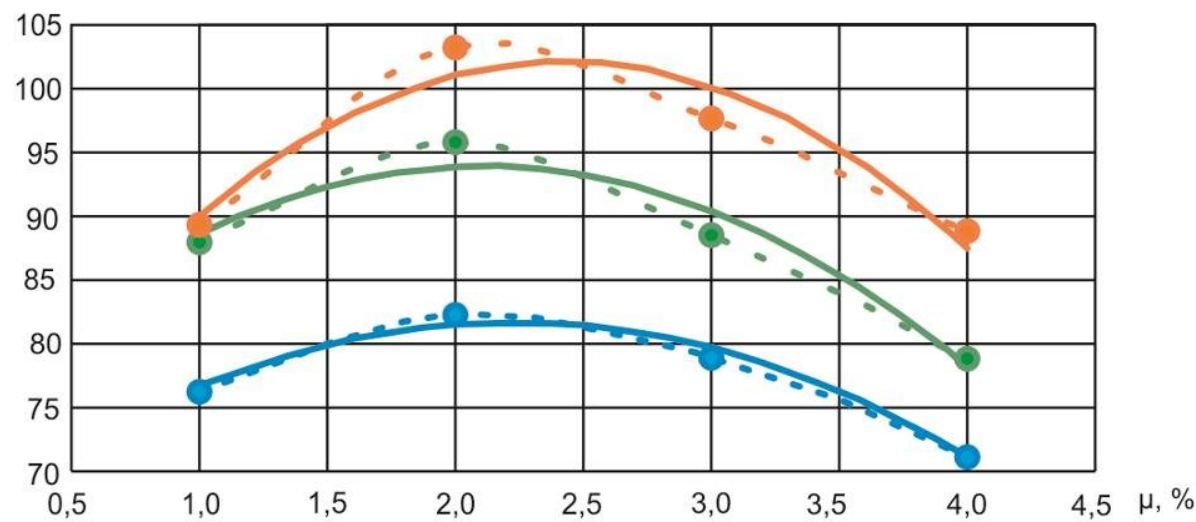

Strength curve of rubcon with polypropylene fibre (theoretical)

Strength curve of rubcon with steel brass plated fibre (theoretical)

Strength curve of rubcon with steel chopped fibre (theoretical)

Strength curve of rubcon with polypropylene fibre (experiment-based)

Strength curve of rubcon with steel brass plated fibre (experiment-based)

Strength curve of rubcon with steel chopped fibre (experiment-based)

Figure 3. Fibreboard compression strength depending on percentage of dispersed reinforcement.

\section{CONCLUSION}

Thus we have obtained analytical and mathematical basis for optimal percentage of rubcon reinforcement with presented types of fibreboards. 


\section{References}

[1] Figovsky Oleg, Beilin Dmitry. Advanced Polymer Concretes and Compounds. CRC Press, New York, 2014, pp. 245.

[2] Yu.M. Borisow, D.V. Panfilov, S.V. Kashtanov, Ye.M. Yudin. Stress - Strain Characteristics of Fiber Polymer Concrete Based on Polybutadiene Binder. Journal "Scientific Israel - Technological Advantages". "Scientific Herald" of Voronezh State University of Architecture and Civil Engineering, Vol.15, № 4, 2013. p. 30-37.

[3] Yu.M. Borisow, A.E. Polikutin, A.C. Chudinov, M.M. Okunev, A.S. Bystrov. Study of T-flanges rubber concrete bended beams. Journal "Scientific Israel - Technological Advantages". "Scientific Herald" of Voronezh State University of Architecture and Civil Engineering, Vol.15, № 4, 2013. p. 65-72.

[4] Yu.B. Potapov., Yu.M. Borisow, S.A. Goshev. X-Ray Fluorescence Spectroscopy Analysis of Pyrolyzate of a Polymer Concrete Based on Polybutadiene Binder. Journal "Scientific Israel - Technological Advantages". "Scientific Herald" of Voronezh State University of Architecture and Civil Engineering, Vol.15, № 4, 2013. p. 11-17.

[5] Yu.M. Borisow, D.V. Panfilov. Fiber-reinforced rubber concretes. Journal "Scientific Israel - Technological Advantages". "Scientific Herald" of Voronezh State University of Architecture and Civil Engineering, Vol.15, № 4, 2013. p. 24-29. 